\title{
Bertrand Competition Under Uncertainty
}

\author{
January 14, 1999 \\ Maarten Janssen and Eric Rasmusen
}

Abstract

Consider a Bertrand model in which each firm may be inactive with a known probability, so the number of active firms is uncertain. This activity level can be endogenized in any of several ways- as whether to incur a fixed cost of activity, as output choice, or as quality choice. Our model has a mixed-strategy equilibrium, in which industry profits are positive and decline with the number of firms, the same features which make the Cournot model attractive. Unlike in a Cournot model with similar incomplete information, Bertrand profits always increase in the probability other firms are inactive. Profits decline more sharply than in the Cournot model, and the pattern is similar to that found empirically by Bresnahan \& Reiss (1991).

Janssen: Department of Economics, H7-22, Erasmus University, 3000 DR Rotterdam, The Netherlands. Fax: 31-10-4081949. Janssen@few.eur.nl.

Rasmusen: Professor of Business Economics and Public Policy and Sanjay Subhedar Faculty Fellow, Indiana University, Kelley School of Business, BU 456, 1309 East 10th Street, Bloomington, Indiana, 47405-1701. (812) 855-9219. Fax: 812-855-3354. Erasmuse@indiana.edu. Http://Php.indiana.edu/ erasmuse. Copies of this paper can be found at

Www.bus.indiana.edu/ erasmuse/@Articles/Unpublished/bertrand.pdf.

We thank David Schmidt and participants in seminars at the Indiana University Dept. of Economics, Erasmus University and CIRANO in Montreal for their comments. 


\section{Introduction}

Consider a carpenter who is asked by a house owner to submit a tender for renovating part of the house. He considers it very likely that if the homeowner has asked for tenders from other carpenters, he gives the job to the carpenter with the lowest tender. However, he also knows there is a chance that the homeowner has not found any other carpenter free to do the work that month and will give the job to him even if his tender is rather high. What price will the carpenter charge?

The price will certainly be above marginal cost. With some probability the carpenter is a monopolist who can charge the monopoly price but with some probability he faces competition. We will model the situation and show that there exists an equilibrium in mixed strategies and that expected industry profits are positive for any number of firms. Moreover, not only do expected profits rise with seller concentration, but the model does reasonably well in explaining the empirical results of Bresnahan and Reiss (1991) on how industry profits increase.

The model allows for many interpretations, in two categories. First, uncertainty about the existence of competitors may arise from uncertainty about consumer search behavior, as in the carpenter example. It may be unclear whether consumers regard rival commodities as perfect substitutes, consumer search costs may be uncertain from the firm's perspective, or consumers may vary in their sophistication. Examples of this range from grocery shopping to buying clothing from mail order companies depending on what catalogs have been received to buying beers that to some consumers all taste alike but to other consumers do not.

Second, uncertainty about the existence of competitors may arise from uncertainty about other sellers' behavior. It may be unclear whether rivals have hit their capacity constraints (in which case they cannot compete for additional consumers), whether rivals have entered yet, whether rivals have grossly overpriced by mistake or ignorance, or whether rivals have temporarily high costs. It may be unclear whether other competitors have also discovered a new market, or in black markets it may be difficult to know the number of firms operating in that market (cf., Janssen and Van Reeven, 1998). Examples of these range from wholesale distribution of candy bars (where in periods of peak demand first one and then another manufacturer may hit capacity) to airline ticket pricing to sales of unusual but not rare antiques or used books. Any of these situations can be modelled as uncertainty over the number of active rivals.

In the two-stage models considered in Section 3, we endogenize the entry decision of firms and show that in three different settings, entry will be a random decision in the equilibrium of the game: (i) auctions, as in the carpenter example), (ii) choosing output or capacity, and (iii) choosing whether to produce high or low quality. An important feature of all three settings will be that the entry decision itself is not observed before firms decide on their pricing behavior. 
The paper is related to several different literatures. A variety of models, of which Salop \& Stiglitz (1977) and Varian (1980) are early examples, have shown that competitive markets can have price dispersion even in equilibrium, with different firms charging different prices for an identical good because of heterogeneous consumer search, some consumers observing more prices than others. The closest of these to the present model is Burdett \&Judd (1983), in which some consumers observe one price, some two prices, some three, and so forth. Our model differs in a number of respects. First, while one possible interpretation is that consumers differ with respect to the number of prices they observe, our model allows for the other interpretations mentioned earlier, interpretations inappropriate for search models. Second, we analyze a strategic model instead of a competitive one, which allows us to study the impact on pricing behavior of the number of firms, a variable not relevant in Burdett \&.Judd (1983). Finally and most important, we treat uncertainty differently. In our model, a firm believes there is a fixed probability that any of its competitors is active, whereas in Burdett and Judd it is the probability that a consumer observes a certain number of prices that is exogenous. The difference lies in what happens as the number of sellers increases. In our model, a seller knows that the probability that at least one other firm is actively competing with it has become closer to one. This drives prices closer to marginal cost, and in the limit we obtain the standard Bertrand outcome. Burdett and Judd still have price dispersion and positive industry profits as the number of firms becomes infinite, because each firm may still be visited by a non-negligible number of consumers who do not search for other prices. In their model, the reason a consumer pays a high price is not that low prices are not available, but that he does not know where to find them.

Also related is Elberfeld and Wolfstetter (1999). They consider a two-stage model in which firms first decide whether to enter and then compete in prices. The outcome of the first stage is known before the firms set their prices in the second stage. Thus, the outcome in the second stage is standard: a firm charges the monopoly price if it is the only firm in the market, otherwise prices are equal to marginal cost. Their main result is that the probability that no firm enters the market increases with the number of potential competitors. Their analysis is closely related to our two-stage game, the important difference being that in our model the entry decision itself is not oberved before firms compete in prices.

Spulber (1995) analyzes a model of Bertrand competition when firms' cost functions are private information. He shows that the model has a unique pure strategy equilibrium in which firms set prices above marginal cost and have positive expected profits. In contrast, the firms in our model do not know how many competitors they have, but assume that any competitor that does exist has the same cost structure. Even though the type of uncertainty varies between Spulber's model and ours, the properties of the market equilibrium are similar: firms set prices above marginal cost and receive positive expected profits. 
Another approach to positive profits under Bertrand competition can be found in the epsilon-equilibrium Bertrand model of Baye \& Morgan (1999). They show that if firms only choose prices to reach within epsilon of their maximal profit, then a mixedstrategy equilibrium exists, in which profits are positive and large compared to the value of epsilon. Thus, if, due to satisficing or managerial slack, firms do not maximize profits completely, the Bertrand model generates more realistic outcomes. The model in our paper also introduces noise which generates a mixed strategy equilibrium, but our noise is the possibility that a customer does not have alternative sellers from whom to buy.

Finally, our model is also of interest for students of auctions. The similarities between Bertrand price competition and first-price sealed-bid auctions is well-known, as, e.g., Baye \& Morgan (1997a, b) explain. Our paper can be regarded as answering the question what is the optimal bid if the number of participantsin a sealed-bid auction is unknown, as is often the case in procurement bids, adding to the literature of which McAfee \& Macmillan (1987) is an example.

Section 2 of the paper lays out the basic model and solves for the mixed strategy equilibrium. Section 3 shows how the entry decision can be endogenized in three different types of two-stage games. These three models also show some of the alternative ways our basic model may be interpretated. Section 4 compares the outcome in the model with that of a Cournot model, and compares the expected industry profits in our model for different numbers of potentially active firms with the empirical findings of Bresnahan and Reiss (1991). Section 5 concludes.

\section{The Model}

Let there be $N$ firms that might produce a homogeneous good. Before deciding price, a firm does not know how many other firms are active in market. The probability a given firm is active is $\alpha$, where $0 \leq \alpha \leq 1$. If $\alpha=1$, the market is described by the Bertrand model of price competition, and the equilibrium price equals marginal cost. If $\alpha=0$ so our one firm is assured of being a monopolist, it will charge the monopoly price. For simplicity, we will assume that there is one consumer, who buys at most one unit, and his maximum willingness to pay for the good is $v$. In case of tied prices, the consumer picks a firm randomly. Marginal cost is normalized to 0 .

First, let us establish that there is no symmetric Nash equilibrium with any firm putting positive probability on choosing any particular price on the continuum. Suppose Firm 1 (without loss of generality) charges price $p^{\prime}$ with positive probability $\theta$, rather than mixing over a continuous range of prices and putting infinitesimal probability on each. Putting positive probability on $p^{\prime}=0$ is not profit maximizing, because if the firm charged the monopoly price of $v$ instead on those occasions it would have an expected payoff of $(1-\alpha)^{N-1} v$, so let us focus on $p^{\prime}>0$. 
If $p^{\prime}>0$, and both firms are putting positive probability $\theta$ on $p^{\prime}$, then with positive probability $\theta^{2}$ they will both charge $p^{\prime}$ and they will each have a contribution of $\left(\theta^{2} / 2\right)\left(p^{\prime}-0\right)$ towards their expected profits. Firm 1 ccould increase its expected profit, however, by deviating to putting zero weight on $p^{\prime}$ and positive weight on $p^{\prime}-\epsilon$, for sufficiently small $\epsilon$. This would replace the expected profit of $\left(\theta^{2} / 2\right)\left(p^{\prime}-0\right)$ with the larger expected profit of $\left(\theta^{2}\right)\left(p^{\prime}-\epsilon\right)$. Thus, it cannot be that both firms put positive probability on any $p^{\prime}$ in equilibrium.

Let us then consider a situation in which only Firm 1 chooses $p^{\prime}$ with positive probability mass. There then exists a neighborhood around $p^{\prime}$ where prices are not chosen with a strictly positive probability mass. We distinguish two possibilities. First, there exist a neighborhood $\left[p^{\prime}, x\right)$ with $x>p^{\prime}$ such that the probability that Firm 2 charges a price in the neighborhood equals 0 . This cannot be an equilibrium, as Firm 1 can increase $p^{\prime}$ without reducing its chance of winning the customer. Second, there exist a neighborhood $\left(p^{\prime}, x\right)$ with $p^{\prime}<x$ such that the probability that Firm 2 charges a price in the whole neighborhood is strictly positive. This can also not be part of an equilibrium, however, as Firm 2 has an incentive to shift probability mass from prices just above $p^{\prime}$ to prices just below it. Hence, there cannot be any equilibrium in which only one firm puts strictly positive probability on any single price. In conjunction with the previous paragraph, this means that there is no equilibrium in which any firm chooses any price with positive probability mass.

Second, the support over which a firm mixes in equilibrium is connected. Consider hat would happen if Firm 1 randomized over an unconnected support, which would include at least two intervals, denoted by $\left[\beta_{1}, \gamma_{1}\right]$ and $\left[\beta_{2}, \gamma_{2}\right]$. It is easy to see that an optimal (mixed strategy) response of Firm 2 does not include prices in the interval $\left[\gamma_{1}, \beta_{2}\right]$. In this case, there exists, however, an $\epsilon>0$ such that Firm 1 will not be indifferent between setting a price of $\gamma_{1}-\epsilon$ and setting a price of $\beta_{2}+\epsilon$. Thus, a necessary condition for Firm 1 randomizing over $\left[\beta_{1}, \gamma_{1}\right]$ and $\left[\beta_{2}, \gamma_{2}\right]$ is violated.

Let us therefore construct an equilibrium in mixed strategies with the strategies having a continuous and compact support. Let $F_{i}(p)$ be the probability that firm $i$ charges a price smaller than $p$. The expected payoff to firm $i$ of charging a price $p_{i}$ when all other firms choose a mixed strategy according to $F(p)$ is

$$
\pi_{i}\left(p_{i}, F_{i}(p)\right)=\Sigma_{k=0}^{N-1}\left(\begin{array}{c}
N-1 \\
k
\end{array}\right)(1-\alpha)^{k}\left[\alpha\left(1-F\left(p_{i}\right)\right)\right]^{N-k-1} p_{i} .
$$

This expression can be explained in the following way. The probability that exactly $N-k-1$ out of the other $N-1$ firms besides Firm $i$ are active is equal to

$$
\left(\begin{array}{c}
N-1 \\
k
\end{array}\right)(1-\alpha)^{k} \alpha^{N-k-1} \text {. }
$$

The expected payoff to firm $i$ when exactly $N-k-1$ firms are active and when it charges a price of $p_{i}$ is equal to $p_{i}$ times the probability that each of these $N-k-1$ 
firms charges a price that is larger than $p_{i}$, which is $\left(1-F\left(p_{i}\right)\right)^{N-k-1} p_{i}$. Multiplying these two terms and summing up over all $k$ gives the expression above.

Expression (1) is, of course, nothing but an application of the Binomial Theorem, and a standard result says that

$$
\sum_{k=0}^{N-1}\left(\begin{array}{c}
N-1 \\
k
\end{array}\right) a^{k} b^{N-k-1}=(a+b)^{N-1} .
$$

Applying equation (3) to the profit equation (1), we obtain

$$
\pi\left(p_{i}, F_{i}(p)\right)=\left[1-\alpha F\left(p_{i}\right)\right]^{N-1} p_{i} .
$$

In equilibrium, firm $i$ must be indifferent between all pure strategies that are in the support of the mixed strategy distribution. Hence, it must be that on some interval of prices the derivative of expression (4) with respect to $p_{i}$ equals zero. Thus, a necessary condition for any equilibrium in continuous mixed strategies is

$$
\left[1-\alpha F\left(p_{i}\right)\right]^{N-1}-(N-1)\left[1-\alpha F\left(p_{i}\right)\right]^{N-2} \alpha f\left(p_{i}\right) p_{i}=0,
$$

or

$$
1-\alpha F\left(p_{i}\right)-\alpha(N-1) f\left(p_{i}\right) p_{i}=0,
$$

where $f$ is the density function associated with cumulative distribution function $F$.

It is a matter of straightforward calculations to show that the solution to differential equation (6) is

$$
F\left(p_{i}\right)=\frac{1-(1-\alpha)\left(\sqrt[N-1]{\frac{v}{p_{i}}}\right)}{\alpha}
$$

for $(1-\alpha)^{N-1} v \leq p_{i} \leq v$.

Result (7) implies that there is a unique symmetric equilibrium with compact support, and we have shown earlier that an equilibrium in pure strategies does not exist. These results are stated in Proposition 1.

Proposition 1. The unique symmetric equilibrium of the Bertrand model with an uncertain number of competitors is in mixed strategies and the distribution function of a player's strategy is

$$
F\left(p_{i}\right)= \begin{cases}0 & \text { for } \quad p_{i} \leq(1-\alpha)^{N-1} v \\ \frac{1-(1-\alpha)\left(\sqrt\left[N-1 \sqrt{\frac{v}{p}}\right)\right]{\alpha}}{\alpha} & \text { for } \quad(1-\alpha)^{N-1} v \leq p_{i} \leq v \\ 1 & \text { for } \quad p_{i} \geq v\end{cases}
$$


Price dispersion is a well-known outcome in real-world markets. Warner \& Barsky (1995), for example, sampled prices at various stores in Michigan for a number of identical single products and found considerable dispersion. ${ }^{1}$ Thus, the mixed strategy we found is quite consistent with reality.

Figure 1 shows the cumulative density for different values of $N$ using equation (8) with $\alpha=.2$ and $v=100$ (prices are at intervals of 1 , connected). As $N$ increases, each firm chooses relatively low prices with higher probability. As $N$ becomes large, the cumulative density function approaches 1 for all values of $p$ that are strictly positive. Of course, the equilibrium price under perfect competition is also equal to 0 . The perfectly competitive outcome can be regarded as the limit case of the present model when the number of firms becomes very large.

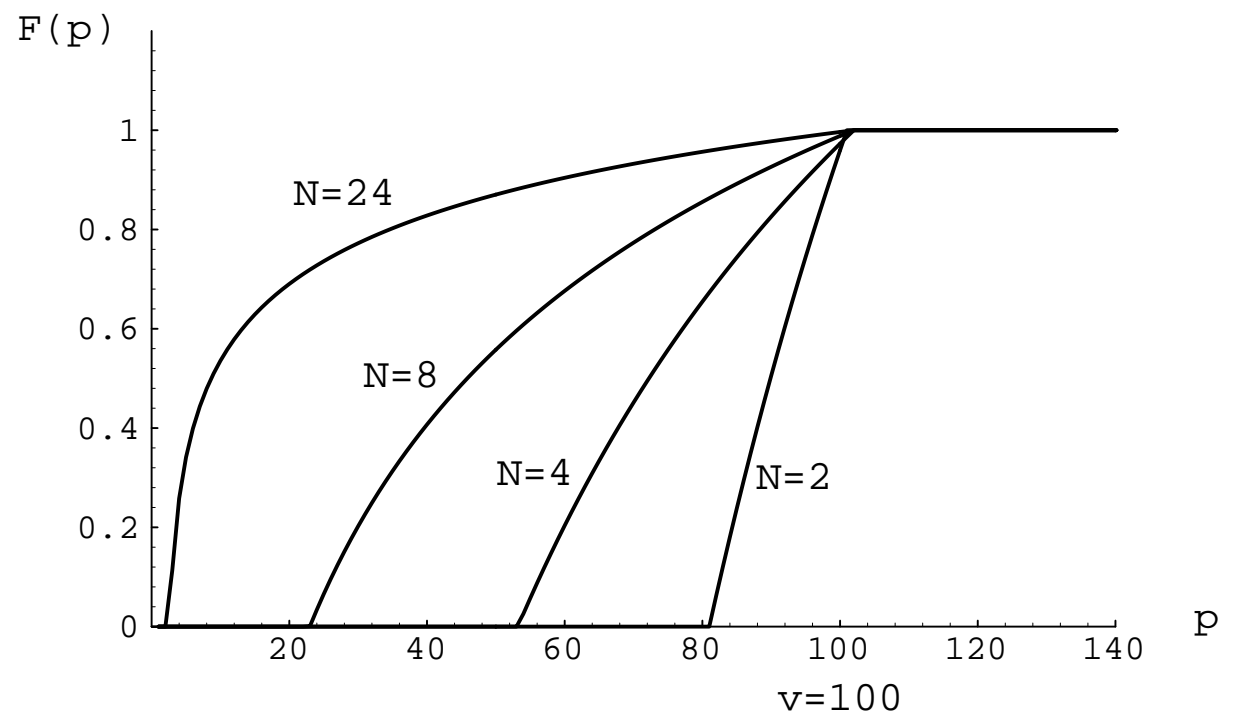

\section{Figure 1: Equilibrium Price Distributions as Industry Concentration}

Rises $(\alpha=.2, v=100)$

The intuition is straightforward. As the number of potential competitors increases, the probability of at least one other firm actively producing the same product rises. With greater probability of competition, the firm reduces its prices. In the limit, a firm is extremely likely to have at least one active competitor. Standard Bertrand competition comes into effect and each firm charges a price equal to marginal cost.

Expected profit for one firm can be found using the pure strategy profit from charging $p=v$. Since the firm is active with probability $\alpha$, that profit is

$$
\pi_{i}=\alpha(1-\alpha)^{N-1} v .
$$

\footnotetext{
${ }^{1}$ See Tables I and III of Warner and Barsky (1995). They found, for example, that a GI Joe had prices of $3.88,2.93,2.69,2.96,2.84,2.96$, and 2.69, while and a Huffy Vortex unassembled boy's bicycle had prices of $73.47,99.99,112.63,119.99,119.99$, and 18.70 .
} 
Note that individual profit is declining in $N$ and its sum, industry profit, is equal to ${ }^{2}$

$$
N \alpha(1-\alpha)^{N-1} v .
$$

Let $\Pi_{b}$ denote expected industry profit under Bertrand competition of this kind given that at least one firm is active. The profit in equation (10) can be written as

$$
\sum_{i=1}^{N} \pi_{i}=N \alpha(1-\alpha)^{N-1} v=(1-\alpha)^{N}(0)+\left[1-(1-\alpha)^{N}\right] \Pi_{b},
$$

yielding

$$
\Pi_{b}=\frac{N \alpha(1-\alpha)^{N-1} v}{1-(1-\alpha)^{N}} .
$$

To see how industry profit changes with $N$, note (after some algebra) that

$$
\frac{d \Pi_{b}}{d N}=\left[\frac{\left(1-(1-\alpha)^{N}\right)+N \log (1-\alpha)}{\left(1-(1-\alpha)^{N}\right)^{2}}\right]\left[\alpha(1-\alpha)^{N-1} v\right]
$$

Derivative (13) is well-defined, even though only integer values of $N$ have an economic interpretation. Its sign is the same as the sign of

$$
1-(1-\alpha)^{N}+N \log (1-\alpha) .
$$

For $N=1$, expression (14) becomes $\alpha+\log (1-\alpha)$, which is negative because $\alpha<$ 1. For larger $N$, expression (14) becomes even more negative, because its derivative with respect to $N$ is $-(1-\alpha)^{N} \log (1-\alpha)+\log (1-\alpha)=\log (1-\alpha)\left[1-(1-\alpha)^{N}\right]<0$. Thus,

$$
\frac{d \Pi_{b}}{d N}<0,
$$

and profits fall as the number of firms increases.

In the appendix it is shown that we can say more, namely

$$
\frac{d^{2} \Pi_{b}}{d N^{2}}>0
$$

This means that profits are convexly decreasing in the number of firms in the industry, so the shape shown in the numerical examples graphed in Figure 2 in Section 4 would be found for any example.

\footnotetext{
${ }^{2}$ Note that although the profits of the different firms are not independent, the expected profits are, so this summation is legitimate.
} 


\section{More General Demand Structures}

So far the assumption has been that the quantity demanded is one unit for all prices smaller than $v$ and zero otherwise. Here, we will consider a more general demand function, which we denote by $D(p)$. For simplicity we will restrict ourselves to the case $N=2$. We will impose one condition on this demand function, namely that $p D(p)$ is increasing in $p$ for $p<p_{m}$, where $p_{m}$ is the monopoly price. Most demand function that are commonly employed satisfy this condition. It is satisfied, for example, if $p D(p)$ is concave in $p$.

Assumption 4.1. The function $p D(p)$ is increasing and differentiable on $\left[0, p_{m}\right)$.

For general demand functions, the expected profit of firm 1 when firm 2 chooses a price according to the cumulative mixed strategy distribution $F_{2}(p)$ is given by

$$
\pi_{1}\left(p_{1}, F_{2}(p)\right)=(1-\alpha) p_{1} D\left(p_{1}\right)+\alpha\left(1-F_{2}\left(p_{1}\right)\right) p_{1} D\left(p_{1}\right) .
$$

A necessary condition for an equilibrium in mixed strategies with continuous support to exist is that on a certain domain of prices

$$
\left[(1-\alpha)+\alpha\left(1-F_{2}\left(p_{1}\right)\right)\right]\left[D\left(p_{1}\right)+p_{1} D^{\prime}\left(p_{1}\right)\right]-\alpha f_{2}\left(p_{1}\right) p_{1} D\left(p_{1}\right)=0 .
$$

One can show that the solution to differential equation (18) is given by

$$
F_{2}(p)= \begin{cases}0 & \text { if } p \leq \underline{p} \\ \frac{1}{\alpha}\left[1-\frac{(1-\alpha) p_{m} D\left(p_{m}\right)}{p D(p)}\right] & \text { if } \quad \underline{p}<p \leq p_{m} \\ 1 & \text { if } \quad p>p_{m}\end{cases}
$$

A similar solution holds for Firm 1. It is clear that equation (19) is similar to equation (12) and the results of the basic model generalize to more general demand functions. Note that from the solution for $F_{i}(p)$ it is clear why we have to impose a condition on demand: A necessary and sufficient condition for $F_{i}(p)$ to be increasing in $p$ is that $p D(p)$ is increasing in $p$ for all values of $p$ smaller than $p_{m}$. In the present case it is impossible to provide an explicit solution for the domain of prices over which a firm randomizes. It is clear that the upper bound is given by $p_{m}$. This is because even if the other firm does not exist, it is not optimal to set a higher price. The lower bound of the domain, denoted by $\underline{p}$, is defined implicitly by the condition $\underline{p} D(\underline{p})=(1-\alpha) p_{m} D\left(p_{m}\right)$ As $p D(p)$ is increasing in $p$ for $p<p_{m}, \underline{p}$ is uniquely defined in this way. 
Industry profits may be calculated as in Section 2 and equals

$$
\Pi_{b}=\frac{N \alpha(1-\alpha)^{N-1} p_{m} D\left(p_{m}\right)}{1-(1-\alpha)^{N}} .
$$

\section{Endogenizing Entry}

In this section, we consider three "front-end" games that endogenize whether a firm is active. We will limit the games to two potential firms each, since our aim is simply to illustrate how the probability $\alpha$ in the previous model might arise. Section (i) is a standard model of entry that requires a fixed cost. A firm does not know whether the other firm has entered when it must choose its price. Section (ii) is a model of output or capacity. Two firms choose how much to produce before they set their prices. When setting prices they do not know the quantity chosen by the other firm. Section (iii) is a model of product quality, where firms set prices not knowing which quality the other firm has chosen. In all these models, the activity choices of firms is random in the symmetric equilibria.

\section{(i) A Model with a Fixed Entry Cost}

Consider the following two-stage extension of the basic model. In the first stage both firms decide whether or not they enter the industry. There is a fixed entry cost denoted by $F$ with $F$ less than $v$, the consumer's reservation price. At the beginning of the second stage the firms have not observed whether the other firm has entered or not. In the second stage, the firms set a price if they entered in the first stage. One example is a sealed bid auction with an entry fee, a common situation in government procurement: it is costly to prepare a bid, and when sending in their bids firms do not know how many competing bidders there are. As the outcome of the first stage is not observed, we can analyze the game as a simultaneous move game.

There are three equilibria. In the two asymmetric equilibria, one firm enters the market and sets a price equal to $v$, while the other firm stays out. In the third, symmetric, equilibrium, both firms are indifferent between entering the market or staying out and they enter the market with a certain probability $\gamma$. Given this probability of entering, each firm chooses a price according to the mixed strategy distribution calculated in Section 2, with $\gamma$ replacing $\alpha$. The expected payoff in the second stage is $(1-\gamma) v$. The only way in which the firms can be indifferent between staying out and entering the market is if $(1-\gamma) v$ equals the fixed entry cost $F$. Thus, $\gamma$ equals $1-F / v$, and expected profits are zero.

\section{(ii) A Model of Output Choice}

Kreps \& Scheinkman (1983) contains a model in which firms compete first in outputs and then in prices. We can do something similar here. Consider a market 
with two consumers, each buying up to one unit each and with a reservation price of $v$. There are two firms, each of whom can decide in the first stage whether to produce 1 or 2 units of a homogeneous output. In the second stage, firms compete in prices not knowing the decision of the other firm in the first stage. The cost of producing 1 unit is normalized to 0 and the cost of producing 2 units is $K<v$, possibly with $K=0$.

There does not exist an equilibrium in pure strategies. It is not an equilibrium for Firm 1 to produce 1 unit and charge a high price, because Firm 2 would respond with 2 units and a slightly lower price, driving Firm 1's profits negative. There cannot be one in which Firm 1 chooses to produce 1 unit and charge a low price, because Firm 2 would respond with 1 unit and a price of $v$, making it profitable for Firm 1 to deviate and produce 2 units and charge slightly less than $v$. Nor can it be an equilibrium for Firm 1 to produce 2 units and charge a price greater than $K$, since Firm 2 would produce 2 units also and charge a lower price, making Firm 1 unprofitable. Finally, it cannot be an equilibrium for Firm 1 to produce 2 units and charge a price of $K$ or less, since Firm 2's best response would be to produce 1 unit and undercut Firm 1 's price, in which case Firm 1 would do better to produce 1 unit and charge a price of $v$.

Let us then consider an equilibrium in mixed strategies: Each firm chooses with probability $\mu$ to produce 2 units, and otherwise produces 1 unit. If a firm happens to choose 1 unit, it will charge a price equal to $v$. The profit of any firm producing 2 units is then

$$
\pi_{i}\left(p_{i}^{2}, F_{-i}^{1}(p), F_{-i}^{2}(p)\right)= \begin{cases}2(1-\mu) p_{i}^{2}+2 \mu\left(1-F_{-i}^{2}(p)\right) p_{i}^{2}-K & \text { if } \quad p_{i}^{2}<v \\ 4 / 3(1-\mu) v+2 \mu\left(1-F_{-i}^{2}(p)\right) v-K & \text { if } \quad p_{i}^{2}=v\end{cases}
$$

where $p_{i}^{2}$ is the price charged by firm $i$ if it has produced 2 units and $F_{-i}^{j}(p)$ is the distribution function with which Firm $-i$ chooses prices if it has produced $j$ units.

It is easy to see that it cannot be optimal to set $p_{i}^{2}=v$. A necessary condition for an equilibrium in mixed strategies is

$$
(1-\mu)+\mu F_{-i}^{2}(p)-\mu f_{-i}^{2}(p) p=0,
$$

or

$$
1-\mu F_{-i}^{2}(p)-\mu f_{-i}^{2}(p) p=0
$$

This equation has the same form as equation (5) for $N=2$. Hence, the solution is given by

$$
F_{-i}^{2}(p)=\frac{1-(1-\mu) \frac{v}{p}}{\mu}
$$

for $(1-\mu) v<p_{i}<v$. 
The profit to either firm of producing 1 unit is

$$
\pi_{i}\left(p_{i}^{1}, F_{-i}^{1}(p), F_{-i}^{2}(p)\right)=\left[1-\mu+\mu\left(1-F_{-i}^{2}\left(p_{i}^{1}\right)\right] p_{i}^{1},\right.
$$

where $p_{i}^{1}$ is the price charged by firm $i$ if it has produced 1 unit.

It is easy to see that given (24), the R.H.S. of $(25)$ reduces to $(1-\mu) v$, which is independent of $p_{i}^{1}$. Hence, given (24), it is optimal to set $p_{i}^{1}=v$.

The profits of producing 1 and 2 units are $(1-\mu) v$ and $2(1-\mu) v-K$. In the mixed strategy equilibrium, these two expressions have to be equal to each other, which implies that $\mu=(v-K) / K$.

So, the entry decision (here: with how many units to enter the Bertrand competition phase) is random and the uncertainty about the existence of a fierce Competitor has been derived endogeneously. ${ }^{3}$

\section{(iii) A Model of Choice of Product Quality}

So far we have considered the situation that two (or more) firms do not know how many competitors they have. An alternative interpretation is that the firms do not know whether consumers consider the products to be perfect substitutes. Let us suppose two firms can produce different qualities of the same product. In the first stage, firms choose whether to produce low $(L)$ or high $(H)$ quality. They know the quality they themselves produce, but they do not know the quality the competitor produces. In addition, the consumer also does not know which quality the firms produce. Low and high quality incur constant marginal production costs of $c_{L}$ and $c_{H}$, with $c_{H}>c_{L}>0$. In the second stage firms choose prices.

Let us consider the case in which a consumer buys one unit of a product: if he buys the high quality, he does not buy the low quality and vice versa. He derives utility of $v_{i}-p$ from consuming quality $i, i=L, H$, where $p$ is the price he pays for the product he buys. The consumer maximizes utility. In particular, if the consumer somehow can infer the quality of the products he will buy the high quality good if and only if $v_{H}-p_{H}>v_{L}-p_{L}$, where $p_{H}$ and $p_{L}$ are the prices charged by the two types of firms. For convenience, assume that $v_{L}>c_{H}$. A special case of the present model, is one in which $v_{H}=v_{L}$. This case can be interpreted as Bertrand competition with firms not knowing of each other whether they have low or high marginal cost (cf., Spulber, 1995).

We will first consider the pricing game under the assumption that for any of the two firms, consumers and the other firm believe that the firm produces low quality with probability $\alpha$, i.e., the firms randomly choose their product quality. Next, we

\footnotetext{
${ }^{3}$ Note that there exists a continuum of equilibria,all in mixed strategies of the form derived in Section 2, indexed by the price a firm sets when producing only 1 unit.
} 
will argue that this assumption can be justified. There are several types of equilibria in the present model. We will consider the case when $c_{H}-c_{L}>2\left(v_{H}-v_{L}\right)$ and show that a continuum of separating equilibria exists, each of which has a structure similar to the one considered in the previous models. ${ }^{4}$

For convenience, we consider the following two restrictions on the out-of-equilibrium beliefs. First, if a consumer observes an out-of-equilibrium price below $c_{H}$, he knows that this price is set by a low-quality firm, because a high-quality firm that maximizes profits would never set such a price. Thus, we impose the belief that $P(\lambda=L \mid p)=1$ for all $p<c_{H}$. (Note that this is implied by the Intuitive Criterion of Cho \& Kreps (1987)). Second, if a consumer observes an out-of-equilibrium price above $c_{H}$, it does not know whether it is set by a high or a low-quality firm. It seems reasonable, however, to impose that the consumer has the same beliefs no matter which price above $c_{H}$ is observed, i.e., $P(\lambda=L \mid p)=\alpha^{\prime}$ for all $p>c_{H}$.

Proposition 2. Suppose $c_{H}-c_{L}>2\left(v_{H}-v_{L}\right)$. For any given level of $\alpha^{\prime}>0$, there exists a continuum of equilibria, indexed by $\lambda$, where $\lambda \in\left[0, \alpha^{\prime}\left(v_{H}-v_{L}\right)\right)$, in which

$$
\begin{aligned}
& p_{H} \quad=c_{H}+\lambda \\
& F\left(p_{L}\right)=\frac{1}{\alpha}\left[1-(1-\alpha)\left(\frac{\left(c_{H}+\lambda-c_{L}\right)-\left(v_{H}-v_{L}\right)}{p_{L}-c_{L}}\right)\right] \\
& \text { for }(1-\alpha)\left[c_{H}+\lambda-\left(v_{H}-v_{L}\right)\right] \leq p_{L} \leq c_{H}+\lambda-\left(v_{H}-v_{L}\right) .
\end{aligned}
$$

Proof. First, we calculate the expected profit of the low-quality firm in equilibrium. When this firm sets a price $p_{L} \leq c_{H}+\lambda-\left(v_{H}-v_{L}\right)$ it is certain that the consumer will buy from it when the other firm produces high quality. Hence, its expected profit is

$$
\pi\left(p_{L} \mid F_{L}(p)\right)=(1-\alpha)\left(p_{L}-c_{L}\right)+\alpha\left(1-F_{L}\left(p_{L}\right)\right)\left(p_{L}-c_{L}\right) .
$$

Substituting the expression for $F_{L}\left(p_{L}\right)$ given in Proposition 2 yields

$$
\pi\left(p_{L} \mid F_{L}(p)\right)=(1-\alpha)\left[\left(c_{H}+\lambda-c_{L}\right)-\left(v_{H}-v_{L}\right)\right]
$$

which is strictly positive.

There are several ways in which the low-quality firm could deviate.

a) Deviating to a price smaller than $(1-\alpha)\left[c_{H}+\lambda-\left(v_{H}-v_{L}\right)\right]$ makes the consumer buy the product for sure, but it yields strictly smaller profits.

(b) Deviating to a price in between $\left[c_{H}+\lambda-\left(v_{H}-v_{L}\right)\right]$ and $c_{H}$ is not profitable, because the consumer will infer that it is a low quality product and will not buy it.

\footnotetext{
${ }^{4}$ If $c_{H}-c_{L}<2\left(v_{H}-v_{L}\right)$, the equilibrium may be separating, partially separating, or pooling, depending on the parameters. We will not discuss that case, since our purpose in this paper is just to show how quality choice can result in mixed-strategy Bertrand competition, not to fully characterize how product quality is chosen.
} 
(c) The firm could deviate by setting $p_{L}$ in the interval $\left[c_{H}, c_{H}+\lambda\right)$. Given the out-of-equilibrium beliefs we specified, the consumer thinks that there is a probability of $\alpha^{\prime}$ that the good is of a low quality. Thus, the payoff the consumer derives from buying at this price is $\alpha^{\prime} v_{L}+\left(1-\alpha^{\prime}\right) v_{H}-p_{L}$. If the other firm is a high-quality firm, it would set a price of $c_{H}+\lambda$ and the consumer derives a payoff of $v_{H}-c_{H}-\lambda$ from buying at this price. As $\lambda$ is smaller than $\alpha^{\prime}\left(v_{H}-v_{L}\right)$, the last expression is always larger than the first. Similarly, if the other firm happens to produce low quality, the maximum price it will charge is $c_{H}+\lambda-\left(v_{H}-v_{L}\right)$ and the consumer's payoff from buying at such prices is larger than or equal to $\left.v_{L}-\left[c_{H}+\lambda-v_{H}-v_{L}\right)\right]$, which reduces to $v_{H}-c_{H}-\lambda$. Thus, the consumer is always better off buying from the other firm and will not buy at a price in the interval $\left[c_{H}, c_{H}+\lambda\right)$. Hence, it is not beneficial to deviate to such a price.

(d) The low quality firm could deviate by setting its price equal to $c_{H}+\lambda$. The consumer will think that the price is set by a high quality firm and will to choose to buy from the low quality firm with probability $1 / 2$ if the other firm produces high quality and sets its equilibrium price. Accordingly, the payoff of deviating in this way is equal to $(1-\alpha)\left(c_{H}+\lambda-c_{L}\right) / 2$. This is smaller than the equilibrium payoff if $2\left(v_{H}-v_{L}\right)<c_{H}+\lambda-c_{L}$. Given the condition in the proposition, this is the case for all values of $\lambda$.

(e) The low quality firm could set a price $p_{L}>c_{H}+\lambda$. This is a situation similar to (c), the only difference being that the firm considers charging even higher prices. Following the argument under (c), it is clear that the consumer will not buy at such a high price. Accordingly, the low quality firm is not better off deviating from its equilibrium strategy.

Let us now consider the high-quality firm. In equilibrium, the expected payoff of this type of firm is given by $\alpha \lambda / 2$. We consider two possible deviations.

(a) A deviation to a price $p_{H} \leq c_{H}$ yields a non-positive payoff and is therefore not undertaken.

(b) For a deviation to a price $p_{H}$ such that either $c_{H} N<p_{H} \leq c_{H}+\lambda$ or $p_{H}>c_{H}+\lambda$, we can give an identical argument as above under (c) and or (e): the consumer will not buy at this price and, hence, this deviation leads to a lower payoff.

We can conclude that it is not profitable for any type of firm to deviate from their equilibrium strategies. Q.E.D.

The mixed strategy distribution of the low quality firm has the same structure as the mixed strategies we have encountered before. This becomes apparent if we recall that earlier we have assumed that the cost of production is zero ( $\operatorname{set} c_{L}=0$ ) and that the maximum price a firm can set is not anymore given by $v$, but by the price the firm can set to distinguish itself from a high quality firm, i.e., replace $v$ by 
$c_{H}+\lambda-\left(v_{H}-v_{L}\right)$. If we substitute these values into the expression of the mixed strategy equilibrium, we have the same expression as in Section 2.

We will now analyze the firms' quality decision. First, note that there exists an equilibrium in which both firms choose low quality and set prices equal to $c_{L}$. More importantly for our paper, however, there exists a continuum of equilibria, parametrized by $\lambda$, each of which Pareto-dominates the equilibrium just described. In each of these equilibria, firms choose to produce low quality with probability $\alpha$, where $\alpha$ is such that the expected profit of the low quality and the high quality choices are equal to each other. More precisely, for each $\lambda>0, \alpha$ is such that $(1-\alpha)\left[\left(c_{H}+\lambda-c_{L}\right)-\left(v_{H}-v_{L}\right)\right]=\alpha \lambda / 2$.

\section{Comparing Bertrand and Cournot}

Cournot (1838) proposed a model in which $N$ firms simultaneously choose quantities and let the market determine the price. Bertrand (1883) pointed out that entirely different conclusions result if the firms choose prices simultaneously instead. Even though the assumptions of price competition seem more realistic, the quantity model yields more realistic outcomes, because profits are positive, but fall gradually as the number of firms increases. We have shown that this objectionable feature of the Bertrand model disappears when uncertainty about the presence of competitors is taken into account. We will now see what happens to the Cournot model when uncertainty is added, and compare the Bertrand and Cournot models under uncertainty. To make the comparison clearer, we will use linear demand,

$$
p\left(\sum_{i=1}^{N} q_{i}\right)=a-b \sum_{i=1}^{N} q_{i} .
$$

Let us define $q(p)$ as the demand facing a monopolist at a price of $p$, so

$$
q(p)=\frac{a}{b}-\frac{p}{b}
$$

The monopoly price then equals $a / 2$ and the quantity demanded is $a / 2 b$ at that price.

We will compute the expected profits from Cournot and Bertrand for different levels of $N$ to obtain some idea of the effects of concentration in each. 


\section{Bertrand equilibrium}

Applying equation (20) to the case of linear demand, the industry profits in the Bertrand model with uncertainty are

$$
\Pi_{\text {bertrand }}=\frac{N \alpha(1-\alpha)^{N-1} p_{m} D\left(p_{m}\right)}{1-(1-\alpha)^{N}}=\frac{N \alpha(1-\alpha)^{N-1} \frac{a^{2}}{4 b}}{1-(1-\alpha)^{N}} .
$$

Adding uncertainty eliminates the discontinuous behavior of the original Bertrand model. Uncertainty makes a big difference, and the comparative statics become consistent and intuitive. Profits are always positive, but they fall whenever the number of firms or the probability of more firms being active increases. Figure 2 shows this for a particular numerical example with $a=100, b=1, N$ from 0 to 7 , and $\alpha$ from 0 to 1.5

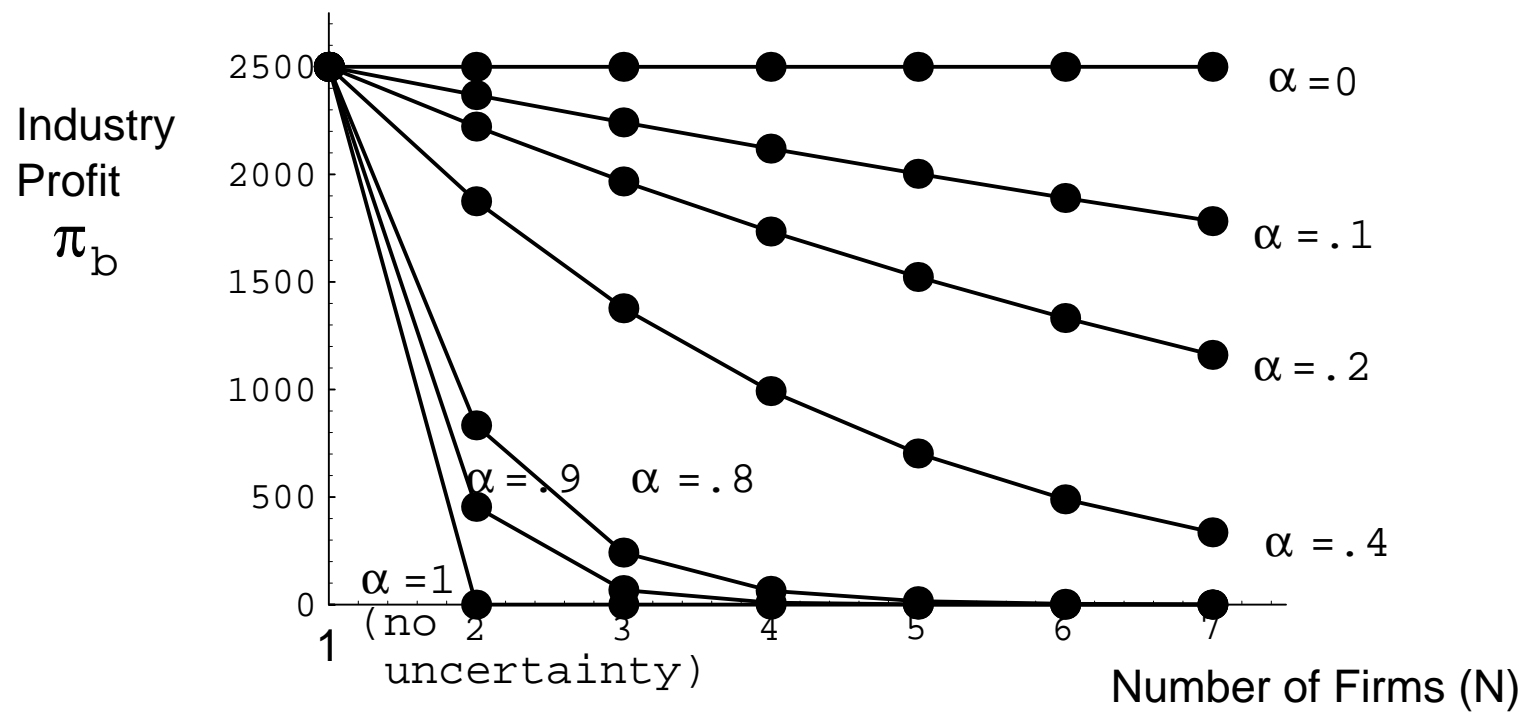

Figure 2: Bertrand Profits For Different Probabilities of Activity, $\alpha$, and Numbers of Firms, $N$

(from Equation (31 (conditional on at least one firm being active)

\footnotetext{
${ }^{5}$ In every case, expected industry profits are conditional upon at least one firm being active. When $\alpha=0$, this is to be interpreted as the probability zero (but nonetheless possible) event that one firm is active and the expected number of other firms is zero.
} 


\section{Cournot Equilibrium}

Now let us compute the Cournot equilibrium. Let $q^{*}$ be the Cournot output we are trying to determine. Firm $i$ 's expected profit if all other firms choose $\mathrm{q}^{*}$ is then

$$
\begin{aligned}
\pi_{i}\left(q_{i}, q^{*}\right) & =\alpha^{N-1}\left[p\left(q_{i}+(N-1) q^{*}\right)\right] q_{i}+\left(\begin{array}{c}
N-1 \\
1
\end{array}\right)(1-\alpha) \alpha^{N-2}\left[p\left(q_{i}+(N-2) q^{*}\right)\right] q_{i} \\
& +\left(\begin{array}{c}
N-1 \\
2
\end{array}\right)(1-\alpha)^{2} \alpha^{N-3}\left[p\left(q_{i}+(N-3) q^{*}\right)\right] q_{i}+\ldots \\
& =\sum_{j=0}^{N-1}\left(\begin{array}{c}
N-1 \\
j
\end{array}\right)(1-\alpha)^{j} \alpha^{N-1-j}\left[p\left(q_{i}+(N-1-j) q^{*}\right)\right] q_{i} .
\end{aligned}
$$

Substituting the linear demand function yields

$$
\begin{aligned}
\pi_{i}\left(q_{i}, q^{*}\right) & =\sum_{j=0}^{N-1}\left(\begin{array}{c}
N-1 \\
j
\end{array}\right)(1-\alpha)^{j} \alpha^{N-1-j}\left[a-b(N-1-j) q^{*}-b q_{i}\right] q_{i} \\
& =\left[a-b \alpha(N-1) q^{*}-b q_{i}\right] q_{i}
\end{aligned}
$$

Differentiating equation (33) with respect to $q_{i}$, setting $q^{*}=q_{i}$, and solving for $q^{*}$ yields

$$
q^{*}=\frac{a}{2 b+\alpha b(N-1)}
$$

Note that if $\alpha=1$, this boils down to $q^{*}=\frac{a}{(N+1) b}$. Adding incomplete information makes no great difference to the Cournot model. If some firms might not be active, each active firm produces somewhat more than it would have done otherwise, but there is no qualitative shift in the equilibrium.

The expected Cournot industry profit conditional upon one firm being active is then

$$
\Pi_{\text {Cournot }}=\frac{a^{2} \alpha N}{b\left[1-(1-\alpha)^{N}\right][2+\alpha(N-1)]^{2}} .
$$

Equation (35) is conditional upon $N q^{*}$ being not so large as to drive the price to zero, which might rationally happen, since a firm would be willing to accept a 
price of zero occasionally as the result of all $N$ firms coincidentally being active and producing a large amount.

Figure 3 depicts Cournot profits for different degrees of activity and concentration, using the same numerical parameters as the Bertrand profits in Figure 2.

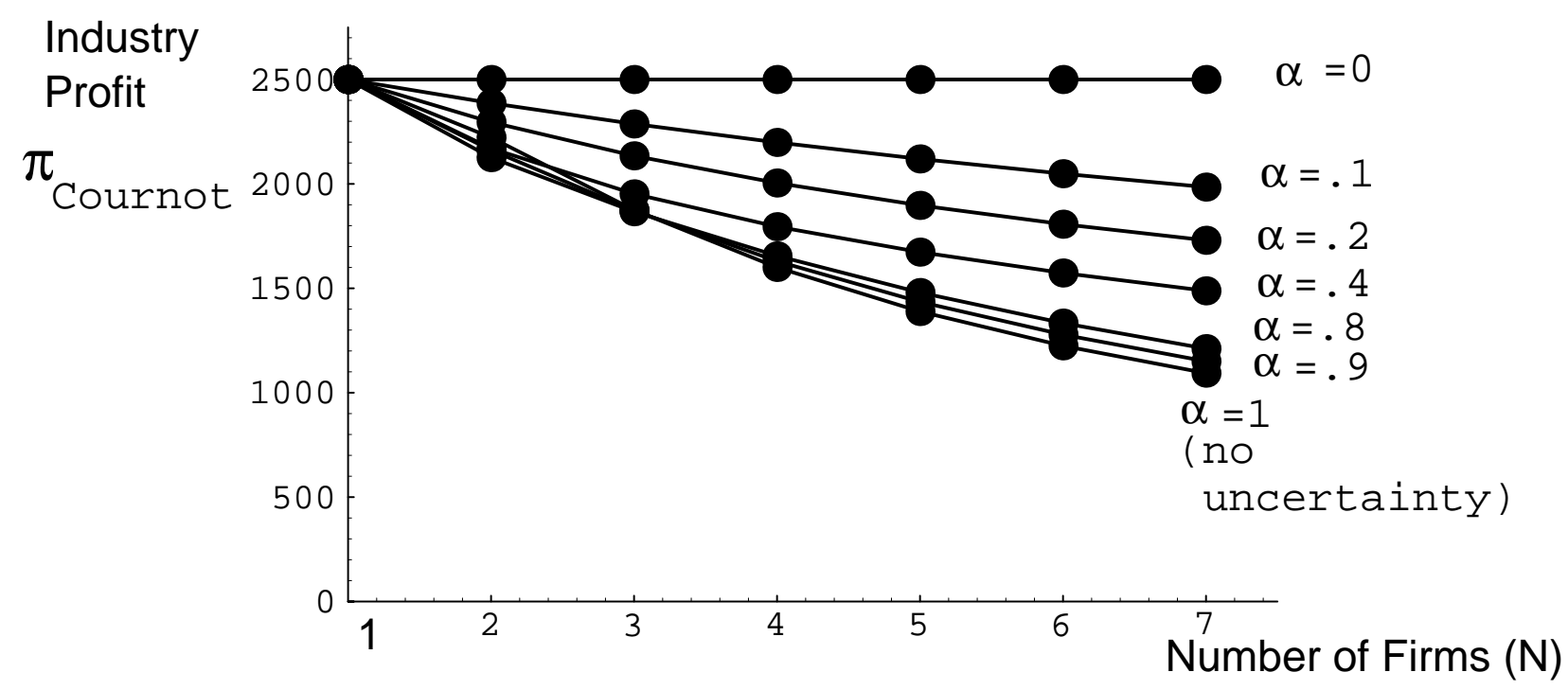

Figure 3: Cournot Profits For Different Probabilities of Activity, $\alpha$, and Numbers of Firms, $N$

(from Equation (35), conditional on at least one firm being active)

Figure 3 shows that depending on the number of firms in the industry, the presence of uncertainty to the Cournot model can either increase or reduce industry profits. Under Cournot competition, a firm expands its output when it expects fewer rivals to be helping push down the price and the next effect on expected industry output is unclear. Conflicting forces are at work in Cournot equilibrium, and the net result is sensitive to particular values of the parameters underlying the model. ${ }^{6}$

\section{Profits and Concentration in Bertrand, Cournot, and the Bresnahan-Reiss Study}

Let us now compare Bertrand and Cournot. Using profit equations (31) and (35), the ratio of industry profits under Bertrand and Cournot competition is

\footnotetext{
${ }^{6}$ The result is reminiscient of the peculiarities of profit per firm in the Cournot model, which can (but do not always) give rise to an incentive for a Cournot firm to split in two to increase its profits, as noted by Salant, Switzer \& Reynolds (1983).
} 


$$
\frac{\Pi_{\text {Bertrand }}}{\Pi_{\text {Cournot }}}=(1-\alpha)^{N-1}\left[1+\frac{\alpha}{2}(N-1)\right]^{2},
$$

which is decreasing in both $N$ and $\alpha$.

Table 1 and Figure 4 show the outcomes of our numerical example for different degrees of concentration under Cournot and Bertrand behavior with certainty and with $\alpha=$.8. (Figure 4 also illustrates the Bresnahan-Reiss empirical result, of which more will be said later.) As we have seen, uncertainty changes the Bertrand model in a crucial way, because profits do become positive and monotonic in the number of firms. The sharp fall in profits moving from monopoly to duopoly under certainty in the Bertrand model is perhaps not so unreasonable as it looks. It is extreme, but it is a limiting result as $\alpha$ goes to one, as Figures 2 and 4 illustrate.

\begin{tabular}{l|rrrrrrr}
\hline \hline Number of Firms $N$ & 1 & 2 & 3 & 4 & 5 & 6 & 7 \\
\hline & & & & & & & \\
Bertrand, $\alpha=1$ & 2500 & 0 & 0 & 0 & 0 & 0 & 0 \\
Bertrand, $\alpha=.8$ (eq. (31)) & 2500 & 833 & 242 & 64 & 16 & 4 & 1 \\
& & & & & & & \\
Cournot, $\alpha=1$ & 2500 & 2222 & 1875 & 1600 & 1388 & 1224 & 1093 \\
Cournot, $\alpha=.8$ (eq. (35)) & 2500 & 2125 & 1867 & 1650 & 1480 & 1333 & 1211 \\
& & & & & & & \\
\hline \hline
\end{tabular}

Table 1: Industry Profits for Different Concentration Levels ${ }^{7}$

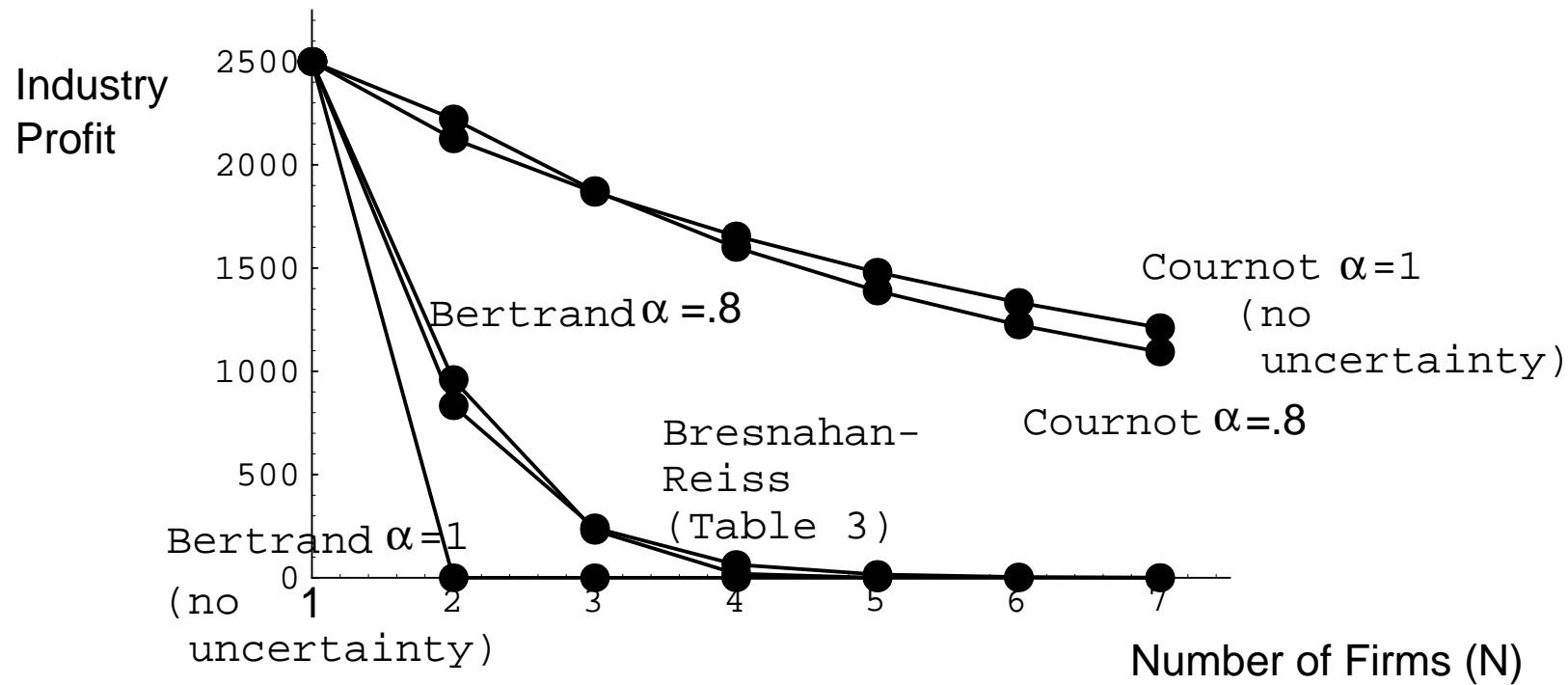

Figure 4: Bertrand and Cournot Profits

\footnotetext{
${ }^{7}$ Numerical calculations and figures use Mathematica. Values are rounded.
} 
Consider the shape of the profit-concentration paths. All the curves in Figures 2 through 4 have convex shapes, if only weakly in the limiting cases, but the curvatures, and therefore the empirical implications, are different. As Figure 4 and Table 1, in particular, show, profits decline much more rapidly in Bertrand than in Cournot. For the parameters chosen, industry profits fall from the monopoly level of 2500 to duopoly profits of 833, triopoly profits of 242, and low levels thereafter. Cournot profits show a much more uniform decline as concentration falls.

Comparison of Figures 2 and 3 shows that for smaller values of the activity probability $\alpha$ the Bertrand profit path becomes flatter and the Cournot path, perhaps more curved, but even at extreme values Cournot does not generate such sharp differences from the addition of one firm to the market.

For most modelling purposes, these models are building blocks, and such subtle differences in the profit-concentration path are unimportant. They are interesting, however, if one wishes to consider Bertrand and Cournot as serious oligopoly models in their own right. Empirically, then, how do profits react to the number of firms? Do they decline to zero with duopoly and then stay constant, as in the original Bertrand model? Do they decline smoothly, as either version of the Cournot model would suggest? Or do they decline rapidly, as the Bertrand model with uncertainty would suggest?

Measuring the relationship between profits and concentration is an old exercise now in some disrepute. ${ }^{8}$ The difficulty is that the usual unit of observation has been the industry. This is natural enough, since one needs a measurement of concentration for each observation. Comparing accounting profits across industries is fraught with danger, however, since accounting profits differ from economic profits in ways that depend on the industry chosen and which are very likely to be correlated with technology, and hence with concentration. Moreover, it is not clear that the concentration-profits path is even the same across industries.

Bresnahan \& Reiss (1991) took a clever empirical approach to the same problem. They took the unit of observation to be the market for a particular product in a particular small town, rather than for many products over the entire United States, and they looked at market size rather than directly at profits. They collected data on the size of a town and the number of dentists there, for example. If a town is very small - say, 500 people - it will have no dentist, since a dentist incurs a fixed cost and could not make any profit there even as a monopoly. If it grows to 800 people, it will have one dentist, since the profits are enough for monopoly, but entry by a second dentist would drive them negative. If the town grows to 1,600 people, however, it may still have only one dentist - if entry by the second dentist would not just split the industry profits, but reduce them.

\footnotetext{
${ }^{8}$ See pp. 349-366 of Carlton \& Perloff 's 1994 industrial organization text for a good discussion of the problems of the profits-concentration literature.
} 


\begin{tabular}{l|rrrrr}
\hline \hline Number of Firms $N$ & 1 & 2 & 3 & 4 & 5 \\
\hline & & & & & \\
Doctors & 0.88 & 1.75 & 1.93 & 1.93 & 1.83 \\
Dentists & 0.71 & 1.27 & 1.39 & 1.36 & 1.28 \\
Druggists & 0.53 & 1.06 & 1.68 & 1.92 & 1.88 \\
Plumbers & 1.43 & 1.51 & 1.51 & 1.55 & 1.49 \\
Tire Dealers & 0.49 & 0.89 & 1.14 & 1.19 & 1.22 \\
& & & & & \\
\hline \hline
\end{tabular}

Table 2: Bresnahan-Reiss Entry Thresholds $s_{i}$ : Original $(\mathbf{1 , 0 0 0 ' s ~ o f ~ i n h a b i t a n t s ~})^{9}$

Bresnahan and Reiss used this approach to estimate the thresholds $s_{i}$ for entry in small markets for a number of industries. Table 2 shows these thresholds in thousands of inhabitants per firm. Table 3 rescales the same numbers to be very roughly comparable with the numerical example used earlier in this paper. ${ }^{10}$ The rescaling is somewhat arbitrary, since the theory of Bresnahan and Reiss is that some quasi-rents remain to cover fixed cost even when the minimum scale for entry flattens out, but it creates a comparison measure for how the intensity of competition changes with the number of firms.

\begin{tabular}{l|rrrrr}
\hline \hline Number of Firms, $N$ & 1 & 2 & 3 & 4 & 5 \\
\hline & & & & & \\
Doctors & 2500 & 430 & 0 & 0 & 0 \\
Dentists & 2500 & 440 & 0 & 0 & 0 \\
Druggists & 2500 & 1550 & 430 & 0 & 0 \\
Plumbers & 2500 & 830 & 830 & 0 & 0 \\
Tire Dealers & 2500 & 1130 & 270 & 100 & 0 \\
& & & & & \\
\hline Average & 2500 & 960 & 230 & 20 & 0 \\
\hline \hline
\end{tabular}

\section{Table 3: Bresnahan-Reiss Entry Thresholds: Rescaled and Rounded $\left(\frac{25\left(s_{m}-s_{i}\right)}{\left(s_{m}-s_{1}\right)}\right)$}

What is significant is how profits flatten out, even though the choice of 0 as the flat level in Table 3 is arbitrary. The empirical result that going from one firm

\footnotetext{
${ }^{9}$ Calculated from Table 5 A of Bresnahan \& Reiss (1991). Note that the entry of .79 in the second row of their original paper is a mistake and should be 1.09, and their Figure 4 illustrates $s_{i} / s_{5}$, not the $s_{5} / s_{i}$ in the legend.

${ }^{10}$ Table 3 's rescaling uses the following procedure.

Define the monopoly level of profits in an industry to be 2500 , and the competitive level to be 0 . Assume that when $s_{i}$ reaches its maximum level $s_{m}$ over $[1,5]$, the competitive level of profits is reached and any further changes are measurement error. Apply the conversion formula $s_{i}^{*}=\frac{25\left(s_{m}-s_{i}\right)}{\left(s_{m}-s_{1}\right)}$, and Table 3 results.
} 
to two is much more important than going from two to three, and that full-fledged competition kicks in very quickly matches the Bertrand model with uncertainty very well, and is inconsistent with the Cournot model.

We do not want to argue that the Bertrand model with uncertainity is the only model that may explain the data presented. Other models in the industrial organizations literature may also explain the data. To illustrate that it is not that easy, however, to explain these data, let us consider the Salop (1979) model as set out in Tirole (1988, pp.282-4) with linear and/or quadratic cost for an exogenously determined value of $N$. With linear (quadratic) cost, the relation between price and $N$ is given by $p=c+t / N$, respecively $p=c+t / N^{2}$, where $t$ is a transportation cost parameter and $c$ is marginal cost. As toptal demand is constant in the Salop model, industry profits are given by $t / N$, and $t / N^{2}$, respectively Confronting these equations with the Bresnahan and Reiss results reveals that profits in the Salop model do not decline exponentially as our model and the empirical results suggests.

\section{Concluding Remarks}

The Bertrand model with uncertainty about the number of competitors is simple, but its properties are both interesting and useful, and, in particular, the extreme transition from monopoly to competition found in the standard Bertrand model disappears. Expected profits are positive, but decline with the number of firms in the industry, and decline in a way that empirical work suggest is more realistic than the way they decline in the Cournot model. We have tried to show that the model is useful both as a simple description of oligopoly and as a building block for other

topics in industrial organization, and this usefulness has already been illustrated in Gwin (1997), and Janssen and Van Reeven (1998). 


\section{Appendix on Convexity}

This appendix shows that Bertrand industry profits are convex in $N$.

The second derivative $\frac{d^{2} \Pi_{b}}{d N^{2}}$ is derived from the first derivative in (13), which can be rewritten as

$$
\frac{d \Pi_{b}}{d N}=\alpha v\left\{\frac{(1-\alpha)^{N-1}}{1-(1-\alpha)^{N}}+\frac{(1-\alpha)^{N-1} N \log (1-\alpha)}{\left[1-(1-\alpha)^{N}\right]^{2}}\right\} .
$$

The derivative of this is

$$
\begin{aligned}
& \frac{d^{2} \Pi_{b}}{d N^{2}}=\alpha v\left\{\frac{\left[1-(1-\alpha)^{N}\right](1-\alpha)^{N-1} \log (1-\alpha)+(1-\alpha)^{N}(1-\alpha)^{N-1} \log (1-\alpha)}{\left[1-(1-\alpha)^{N}\right]^{2}}+\right. \\
&\left.\frac{\left[(1-\alpha)^{N-1} \log (1-\alpha)+(1-\alpha)^{N-1} N \log ^{2}(1-\alpha)\right]\left[1-(1-\alpha)^{N}\right]^{2}+2\left[1-(1-\alpha)^{N}\right](1-\alpha)^{N} \log (1-\alpha)\left[N(1-\alpha)^{N-1} \log (1-\alpha)\right]}{\left[1-(1-\alpha)^{N}\right]^{4}}\right\} . \\
&= \alpha v\left\{2 \frac{(1-\alpha)^{N-1} \log (1-\alpha)}{\left[1-(1-\alpha)^{N}\right]^{2}}+\frac{(1-\alpha)^{N-1} N \log ^{2}(1-\alpha)\left[1-2(1-\alpha)^{N}\right]+(1-\alpha)^{2 N}+2(1-\alpha)^{N}-2(1-\alpha)^{2 N}}{\left[1-(1-\alpha)^{N}\right]^{4}}\right\} \\
&= \alpha v\left\{2 \frac{(1-\alpha)^{N-1} \log (1-\alpha)}{\left[1-(1-\alpha)^{N}\right]^{2}}+\frac{(1-\alpha)^{N-1} N \log ^{2}(1-\alpha)\left[1-(1-\alpha)^{2 N}\right]}{\left[1-(1-\alpha)^{N}\right]^{4}}\right\} \\
&= \frac{(1-\alpha)^{N-1} \log (1-\alpha)}{\left[1-(1-\alpha)^{N}\right]^{2}}\left\{2+\frac{N \log (1-\alpha)\left[1+(1-\alpha)^{N}\right]}{1-(1-\alpha)^{N}}\right\} \alpha v .
\end{aligned}
$$

The first term of this expression is negative because $\log (1-\alpha)$ is negative.

The second term has the same sign as

$$
2-2(1-\alpha)^{N}+N \log (1-\alpha)\left[1+(1-\alpha)^{N}\right] .
$$

We will show that expression (39) is also negative for all $N$ and all $\alpha \in(0,1)$. We will first show that it is negative for $N=1$. In this case we can define $f(\alpha)=$ $2 \alpha+(2-\alpha) \log (1-\alpha)$. It is easy to see that $f(0)=f^{\prime}(0)=0$ and that $f^{\prime \prime}(\alpha)=-\frac{\alpha}{(1-\alpha)^{2}}$, which is strictly negative for all $\alpha>0$. Hence, for all $\alpha \in(0,1), f(\alpha)<0$.

Let us then consider for fixed $\alpha$,

$$
g(N)=2-(1-\alpha)^{N}+N \log (1-\alpha)\left[1+(1-\alpha)^{N}\right]
$$

It can be shown that

$$
g^{\prime}(N)=(1-\alpha)^{N}-1-(1-\alpha)^{N} N \log (1-\alpha)
$$

and that

$$
g^{\prime \prime}(N)=-(1-\alpha)^{N} \log ^{2}(1-\alpha) .
$$


As $g(1)$ and $g^{\prime}(1)$ are strictly negative, we can conclude that expression (39) is negative, so that

$$
\frac{d^{2} \Pi_{b}}{d N^{2}}>0 .
$$


Appendix on Comparison of Bertrand and Cournot profits

This appendix shows that the ratio (36) is decreasing in $N$ and $\alpha$. To see the first, take the derivative with respect to $N$, which is

$$
\begin{aligned}
& \log (1-\alpha)(1-\alpha)^{N-1}\left[1+\frac{\alpha}{2}(N-1)\right]^{2}+\alpha(1-\alpha)^{N-1}\left[\left[1+\frac{\alpha}{2}(N-1)\right]\right. \\
& =\left\{\operatorname { l o g } ( 1 - \alpha ) [ [ 1 + \frac { \alpha } { 2 } ( N - 1 ) ] + \alpha \} ( 1 - \alpha ) ^ { N - 1 } \left[\left[1+\frac{\alpha}{2}(N-1)\right]\right.\right.
\end{aligned}
$$

The sign of is derivative (44) is determined by the sign of the first term. Since

$$
\left[1+\frac{\alpha}{2}(N-1)\right] \geq 1>\frac{-\alpha}{\log (1-\alpha)},
$$

the derivative is negative.

To see that ratio (36) is decreasing in $\alpha$, take the derivative with respect to $\alpha$, which is

$$
\begin{aligned}
& -(N-1)(1-\alpha)^{N-2}\left[1+\frac{\alpha}{2}(N-1)\right]^{2}+(N-1)(1-\alpha)^{N-1}\left[1+\frac{\alpha}{2}(N-1)\right] \\
& =-(N-1)(1-\alpha)^{N-2}\left[1+\frac{\alpha}{2}(N-1)\right]\left[1+\frac{\alpha}{2}(N-1)-(1-\alpha)\right] \\
& =-(N-1)(1-\alpha)^{N-2}\left[1+\frac{\alpha}{2}(N-1)\right]\left[\frac{\alpha}{2}(N+1)\right]
\end{aligned}
$$

which is negative. 


\section{References}

Baye, Michael \& John Morgan (1997a) "Information Transmission, Information Acquisition, and Price Dispersion in 'Thin' Markets," Working paper, Indiana University, Kelley School, Dept. of Business Economics and Public Policy.

Baye, Michael \& John Morgan (1997b) "Necessary and Sufficient Conditions for Existence and Uniqueness of Bertrand Paradox Outcomes, "Working paper, Indiana University, Kelley School, Dept. of Business Economics and Public Policy. Http://php.indiana.edu/ mbaye/bert.pdf.

Baye, Michael \& John Morgan (1999) "Epsilon Equilibria in Bertrand Games: Theory and Experimental Evidence," Working paper, Indiana University, Kelley School, Dept. of Business Economics and Public Policy, January 1999.

Bertrand, Joseph (1883) "Rechercher sur la Theorie Mathematique de la Richesse," Journal des Savants, September 1883. 48: 499-508.

Bresnahan, Timothy \& Peter Reiss (1991) "Entry and Competition in Concentrated Markets," Journal of Political Economy, October 1991. 99: 977-1009.

Burdett, Kenneth \& Kenneth Judd (1983) "Equilibrium Price Dispersion," Econometrica, July 1983, 51: 981-996.

Carlton, Dennis \& Jeff Perloff (1994) Modern Industrial Organization, second edition, New York: HarperCollins College Publishers, 1994.

Cho, In-Koo \& David Kreps (1987) "Signaling Games and Stable Equilibria," Quarterly Journal of Economics, May 1987. 102: 179-221.

Cournot, Augustin (1838) Recherches sur les Principes Mathematiques de la Theorie des Richesses, Paris: M. Riviere \& C., 1938. Translated in Researches into the Mathematical Principles of Wealth. New York: A.M. Kelly, 1960.

Edgeworth, Francis (1897) "La teoria pura del monopolio," Giornale degli economisti, 1925. 40: 13-31. Translated in Edgeworth, Francis, Papers Relating to Political Economy, Vol. I. London: Macmillan, 1925, 111-42.

Elberfeld, Walter \& Elmar Wofstetter (1999) "A Dynamic Model of Bertrand Competition with Entry," International Journal of Industrial Organization, 17: 513525 (1999).

Gwin, Carl (1997) "Special Pricing Agreements as Vertical Restraints," in Three Common Business Practices as Reponses to Asymmetric Information Problems, Ph.D. Dissertation, Indiana University School of Business, July 1997.

Janssen, Maarten C.W. and Peran Van Reeven (1998) "Market Prices and Illegal 
Practices," International Review of Law and Economics , 18: 51-60.

Kreps, David \& Jose Scheinkman (1983) "Quantity Precommitment and Bertrand Competition Yield Cournot Outcomes," Bell Journal of Economics, 14: 326-37 (Autumn 1983).

McAfee, R. Preston \& John Macmillan (1987) "Auctions with a Stochastic Number of Bidders," Journal of Economic Theory, 43: 1-19.

Rasmusen, Eric (1994) Games and Information. 2nd edition. Oxford: Basil Blackwell, 1994.

Salant, Stephen, Sheldon Switzer \& Robert Reynolds (1983) "Losses from Horizontal Merger: The Effects of an Exogenous Change in Industry Structure on CournotNash Equilibrium," Quarterly Journal of Economics, May 1983. 98: 185-99.

Salop, Steven \& Joseph Stiglitz (1977) "Bargains and Ripoffs; A Model of Monopolistically Competitive Price Dispersion," Review of Economic Studies, 44: 493-510 (October 1977).

Spulber, Daniel (1995) "Bertrand Competition When Rivals' Costs are Unknown," Journal of Industrial Economics, March 1995. 43: 1-11.

Varian, Hal (1980) "A Model of Sales," American Economic Review, September 1980. 70: 651-659. "Erratum," June 1981.

Warner, Elizabeth \& Robert Barsky (1995) "The Timing and Magnitude of Retail Store Markdowns: Evidence from Weekends and Holidays," Quarterly Journal of Economics, May 1995. 110: 321-52. 